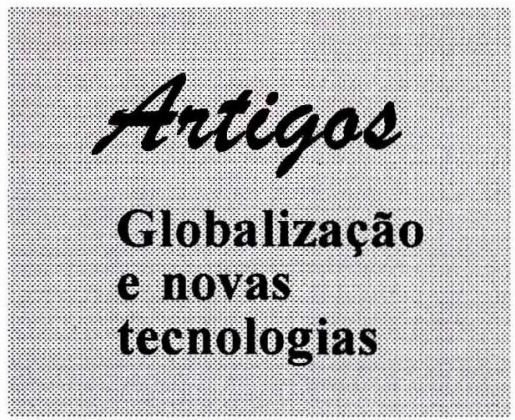

\title{
As novas tecnologias de informação e a geração do conhecimento
}

Aldo de Albuquerque Barreto*

\section{Resumo}

O ambiente de informação sofre o impacto de duas novas condições: um modelo teórico em mudança, em que a relação entre a informação e o conhecimento é privilegiada, e as tecnologias intensas em inovação que modificam, também, as condições de produção, distribuição e uso da informação. Novos reposicionamentos afetam, como resultado, todos os atores do setor de informação, assim como os seus relacionamentos.

Palavras-chave: novas tecnologias em comunicação; novo paradigma profissional; bibliotecário.

Começo, talvez por uma nostalgia do presente, referindo-me ao passado. Volto a 1945, na época do final da Segunda Guerra e ao enorme volume de informação restrita por segredo de guerra e que se tornou pública, isto é, passou a integrar o fluxo formal de informação disponível ao público. IBICT.

* Economista, $\mathrm{PhD}$ em Ciência da Informação e pesquisador titular do CNPq/

Comun. inf., v.1, n. 1, p. 11-17, jan.jjun. 1998 
Nos Estados Unidos foi criado o Office of Scientific Research and Development dirigido pelo Dr. Vannevar Bush, que ainda em 1945 escreve seu famoso artigo "As we may think", em que demonstra sua preocupação pela perda e duplicação de pesquisas, que passaram a integrar o fluxo de informação, como as Leis da Genética de Mendel, perdidas durante anos devido à desorganização da informação.

Ainda em seu famoso e atualmente muito utilizado artigo, baseado na tecnologia existente, o Dr. Bush faz previsões de sua máquina Memmex, que armazenaria e recuperaria a informação através de um relacionamento associativo dos conceitos de um documento. $\mathrm{Da}$ forma como pensamos, diria ele. Idéias, hoje muito parecidas com os documentos hipertexto, ou com a utilização de linguagens multimídia em um documento eletrônico.

Contudo, talvez pela sua preocupação com a organização da informação, tem sido atribuída ao Dr. Bush a idealização do Sistema de Armazenamento e Recuperação da Informação ou "Information Retrieval System", que direciona as práticas informacionais dos últimos cinquenta anos. Tão forte foi seu impacto na ideologia interna do setor de informação, que por vezes a parte passava a determinar ou denominar o todo, na medida em que o Sistema de Armazenamento e Recuperação era considerado o próprio Sistema de Informação. Isto seria uma aberração teórica, pois o usuário se deslocaria da ambiência do sistema para ser colocado dentro dele, como um recurso ou elemento controlado pelo sistema.

$\mathrm{Na}$ verdade, a concepção de sistemas de armazenamento e recuperação da informação só permitia uma frágil interação com o usuário e ainda assim no modo ex-post que era o feedback.

Assim, dentro de uma determinada contemporaneidade de domínio da tecnologia dos sistemas de recuperação de informação, havia um problema bem determinado e uma solução simplista. $O$ problema consistia em como controlar e gerenciar o volume de produção da informação, em um mundo de muitos documentos e com um fluxo de ligação com o usuário e com a sociedade em desordem; $a$ solução seria a busca da ordem através de uma metodologia sistêmica, utilizando fatores de redução, através da (re)formatação da informação, a fim de atender aos requisitos

Comun. inf., v.1, n. 1, p. 11-17, jan./jun. 1998 
técnicos e de produtividade (espaço, tempo) do sistema de recuperação.

A solução técnica operacional trouxe porém uma "economia de informação" indesejável, baseada em três tipos de seleção por exclusão, na formação dos estoques de informação: a primeira seleção é a de documentos que vão entrar para o formar o estoque de informação, os acervos; a segunda seleção transforma o conteúdo dos documentos, porque partes do documento original são selecionadas, para representar o documento como um todo; a terceira seleção consiste em traduzir para descritores as partes selecionadas anteriormente, utilizando uma nova linguagem controlada, não natural, pois em nome da ordem havia que se promover a compatibilidade da linguagem de entrada e da linguagem de saída do sistema.

O sistema de recuperação da informação obedecia, então, a um rígido formalismo técnico e reducionista, que serviu aos propósitos de gerenciamento e controle da informação em uma determinada situação.

Contudo a partir dos anos 80 novos modelos tecnológicos e conceituais vêm provocando uma modificação no posicionamento dos agentes que operam as práticas informacionais, principalmente devido a:

1. uma nova visão conceitual de que a informação se relaciona com o conhecimento e com o desenvolvimento humano;

2. uma queda considerável no custo e na operacionalidade dos arquivos magnéticos;

3. um desenvolvimento acelerado da microeletrônica e de suas tecnologias paralelas;

4. um desenvolvimento acelerado da telecomunicação e de suas tecnologias subordinadas.

A mudança conceitual é tão profunda e importante quanto as modificações do quadro tecnológico. A informação começa a ser entendida, não mais como um item armazenado e passível de recuperação, mas como "estruturas significantes com a competência de gerar conhecimento no indivíduo, em seu grupo, ou a sociedade".

Assim colocada a significação de informação direciona uma nova reflexão. A informação é qualificada como um instrumento

Comun. inf., v.1, n. 1, p. 11-17, jan./jun. 1998 
modificador da consciência do homem e de seu grupo social. Deixa de ser, unicamente, uma medida de organização por redução de incerteza, para ser a própria organização em si. Fica estabelecida uma relação entre informação e conhecimento, que só se realiza se a informação é percebida e aceita como tal, colocando $a$ indivíduo em um estágio melhor, consciente consigo mesmo e dentro do mundo onde se realiza a sua odisséia individual.

Como agente mediador da produção de conhecimento, introduzimos o conceito de assimilação da informação, como um processo de interação entre o indivíduo e uma determinada estrutura de informação, que vem a gerar uma modificação em seu estado cognitivo, produzindo conhecimento, que se relaciona corretamente com a informação recebida. É um estágio qualitativamente superior ao simples uso da informação. Não pretendemos aqui levantar grandes questões filosóficas sobre a Teoria do Conhecimento. Aceitamos que conhecimento é toda a alteração provocada no estado cognitivo do indivíduo, isto é, no seu estoque mental de saber acumulado, proveniente de uma interação positiva com uma estrutura de informação. Esta modificação altera o seu estoque de saber: ou porque acrescenta novo saber, ou porque sedimenta saber já estocado, ou porque modifica saber anteriormente estocado. Se nenhuma alteração ocorrer não aconteceu a assimilação da informação e, portanto, não se efetivou a relação informaçãoconhecimento.

Assim é nossa crença que o destino final, o objetivo da informação e de suas unidades gestoras, é promover o desenvolvimento do indivíduo, de seu grupo e da sociedade. Entendemos desenvolvimento, de uma forma ampla e geral, como um acréscimo de bem-estar, um novo estágio de qualidade de convivência, alcançado através da informação.

As duas funções básicas de uma unidade de informação, responsáveis pela realização do objetivo final são: a função de produção da informação e a função de transferência da informação.

A primeira função é definida como a produção de informação, que se operacionaliza com práticas bem definidas, apoiadas em um processo de transformação, que se orienta por uma racionalidade técnica, que lhe é específico; estas práticas são representadas por atividades relacionadas com a reunião, a seleção, o processamento 
e o armazenamento da informação, por exemplo. A produção de informação se acumula continuamente para formar os estoques de informação, que são quantidades estáticas de informação armazenadas em acervos, em geral, de bibliotecas, de arquivos, de museus, de bases de dados, de redes ou de sistemas de informação. Os estoques estáticos de informação são indispensáveis ao processo de geração de conhecimento. Mas por si só não efetivam este processo.

A produção ou a geração de conhecimento (no indivíduo, seu grupo ou sociedade) ocorre em um processo mais amplo, intermediado pela segunda função, que é a função de transferência da informação.

A assimilação da informação é a finalização de um processo de aceitação sua que transcende o seu uso. É um ato de assimilação. A assimilação da informação cria conhecimento no indivíduo (receptor) e em sua ambiência. É a virtualização dos estoques possíveis de informação. Este é o destino final do fenômeno da informação: criar conhecimento modificador e inovador do indivíduo e do seu contexto. Conhecimento, que referencie tanto o indivíduo como seu contexto a um melhor estágio de desenvolvimento.

Contudo, o indivíduo e seu contexto não são homogêneos como o é o tratamento técnico, que opera a formação dos estoques de informação. A realidade em que se pretende que a informação atue para gerar conhecimento é fragmentada em suas condições políticas, econômicas e culturais. Os habitantes desta realidade são multifacetados em suas competências para absorver a informação, diferenciando-se, por exemplo, em aspectos tais como: grau de instrução, nível de renda, acesso aos códigos formais de representação simbólica, acesso e confiança aos canais de transferência da informação, estoque pessoal de conhecimento acumulado e competência na decodificação e na utilização do código lingüístico comum.

Harmonizar o estoque de informação produzida e disponível na sociedade, com a sua transferência visando a assimilação, que gera conhecimento é a intenção maior de todos àqueles que trabalham com a informação.

Os fatores tecnológicos determinados por uma tecnologia intensa em inovação e velozmente mutante são os outros parceiros

Comun. inf., v.1, n. 1, p. 11-17, jan./jun. 1998 
responsáveis pelo reposicionamento dos agentes do setor de informação, que atinge o produtor de estoques de informação o documento de informação, a transferência da informação e sobretudo a relação do usuário com todos os demais.

Estas mudanças estão colocadas no que tem sido chamado de:

a) hiperinteratividade - que representa a possibilidade de acesso em tempo real pelo usuário a diferentes estoques de informação e à múltiplas formas de interação entre o usuário, os estoques e as estruturas de informação contidas neles. A interatividade modifica a relação usuário-tempo-informação, reposiciona os produtores de informação, o acesso à informação, sua distribuição e as próprias inscrições de informação.

b)hiperconectividade - que se relaciona com a possibilidade do usuário de informação em deslocar-se no momento de sua vontade de um espaço de informação para outro, de um estoque de informação para outro. O usuário passa a ser o seu próprio mediador de escolha de informação, o determinador de suas necessidades. Passa a ser o julgador de relevância do documento e do estoque que o contém em tempo real, como se estivesse colocado virtualmente dentro do sistema de armazenamento e de recuperação da informação. A hiperconectividade reposiciona a relação usuárioespaço-informação.

O usuário do IRS deixa sua posição de espectador do processo de recuperação da informação e atua com os estoques de informação diretamente. Interage com documentos (hipertexto) e usa linguagens multimídia. Questiona ou não aceita mais a superorganização dos sistemas de recuperação da informação, que procuram tirá-lo do lugar conquistado, o de participante virtual do sistema, para transformá-lo de novo em espectador de um processo de transferência da informação, com o distanciamento brechtiano que caracterizou a interação do feedback.

Nessa nova posição o usuário de informação percebe, ainda, que não é suficiente ter somente acesso à informação, mas que necessita, também, conhecer o seu significado, estar apto a reelaborar esta informação em seu proveito e no da comunidade em que vive.

Comun. inf., v.1, n. 1, p. 11-17, jan./jun. 1998 


\section{Abstract}

The information environment has had the impact of two new conditions: a theoretical framework, in which the relation between information and knowledge is underlined, and a highly intensive new technology in innovation that has changed the production, distribution and use of information. These are the new placements that are rearranging the actors of the information scene.

Key words: new technologies in communication; new professional paradigm; librarian.

\section{Referências bibliográficas}

BARRETO, A de A. A informação e a transferência de tecnologia. Brasília: SENAI/IBICT, 1993.

BARRETO, A de A. A informação e o cotidiano urbano. Rio de Janeiro: IBICT/ECO, 1991.

BARRETO, A de A. A transferência de informação, o desenvolvimento tecnológico e a produção de conhecimento. Informare, v. 1, n.2, jul.dez. 1995.

BOULDING, K. Knowledge and life in society. Michigan: University of Michigan Press, 1960.

BUTCHER, H.J. A inteligência humana. São Paulo : Perspectiva, 1968.

FARRADANE, J. Knowledge, information and information science. Journal of Information Science, London, v.2, n.2, 1980.

FARRADANE, J. The nature of information. Journal of Information Science. London, v. 1, n.3, 1970.

HABERMAS, J. Conhecimento $e$ interesse. Rio de Janeiro : Guanabara, 1987.

HUMPHREY, N. Uma história da mente: A evolução e a gênese da consciência. Rio de Janeiro : Campus, 1994.

LAMBERTON, D.M. (Ed). Economics of information and knowledge, London : Penguin, 1971.

LANCASTER, F. W. The measurement and evaluation of library services. New York: Information Resource Press, 1977.

LÉVY, P. O que é o virtual. São Paulo : Editora 34, 1996.

ORIN, E. O método, o conhecimento do conhecimento. Lisboa : Biblioteca Universitária, 1986. 